\title{
Changes in the perception of self-image and the sense of purpose and meaning in life, among women who lost their child before birth
}

\begin{abstract}
BACKGROUND
The article is concerned with descriptions of self-image and the sense of purpose in life, among women who have experienced the loss of a child through miscarriage, premature birth or stillbirth. The loss of a child at the prenatal stage is a very difficult experience for the mother. Such women experience a wide range of emotions and often show unpredictable behaviours, both of which can influence their future functioning and mental health.
\end{abstract}

\section{PARTICIPANTS AND PROCEDURE}

The goal of the current study was to look at the differences between women who had given birth to a healthy child, and those who lost an unborn child. A total of 125 women participated in the study. The Gough and Heilbrun Adjective Check List (ACL) as well as Wong's Personal Meaning Profile tests were used as research methods.

\section{RESULTS}

As expected, significant differences were observed between the two groups in terms of their self-image and perceived sense of purpose and meaning in life. Women who lost an unborn child had a tendency for lower self-esteem, higher perceived guilt and lower needs.

\section{CONCLUSIONS}

The obtained results suggest the need for observation of mothers who experienced a prenatal child loss. The access to professional help and support from physicians and, more importantly, psychologists and therapists has an influence on their self-image, and the sense of purpose in both the present and the future. Adequate professional assistance has an influence on their family relations and their ability to plan another pregnancy (further attempts at conception), without a perception of guilt associated with the loss of the previous child.

\section{KEY WORDS}

child loss; self-image; sense of purpose and meaning in life; miscarriage 


\section{BACKGROUND}

Experiencing child loss during pregnancy and in the perinatal period is a concern for both medical and psychological research. Both sciences analyse the genesis, factors, course as well as the consequences of child loss. The fields of medicine dealing with prenatal child loss include the pathology of pregnancy or prenatal diagnostics, as well as research into the ways to sustain high-risk pregnancies.

In terms of human psychology, the loss of a child is a very painful experience for a family. It has an impact on both the mother and the father of the child, as well as other family members, each to a different degree. In addition, not every woman will go through the loss in the same way. For most couples, the period of expecting offspring is a time of great joy. Even at the earliest stages of pregnancy they may personalize the expected baby by choosing a name, or taking care to gather the items needed after the birth.

Lachelin wrote in 1998 that the more advanced the pregnancy, the more relatives and friends will know about it, and more preparations will be made for the new child such as decorating a new room or buying clothes and toys. The loss of a child at later stages of pregnancy is usually associated with more pain, though in the case of a long awaited pregnancy, the loss might be perceived equally strongly at any stage of the child's development in the mother's womb.

Looking at the theoretical descriptions of fulfilled motherhood versus the child loss, it is possible to see differences in experienced emotions and behaviours between the alternative endings to a pregnancy. This leads to a hypothesis about differences in self-image and the perception of one's situation. The study conducted by Barton-Smoczyńska (2006) observed changes in self-perception, and the main long-term consequences of the child's death were a decrease in faith in oneself, weakening of one's ego and a passive attitude. According to Lachelin, women who lost their child will experience grief, anger, self-pity as well as perception of lack of self-worth, all of which are unheard of in the descriptions of women after giving birth to a healthy child (Lachelin, 1998). Moreover, the research on the self-image of women during pregnancy shows that expecting mothers tend to ascribe to themselves a higher number of negative features and have a tendency to self-denial (Swanson, 1999; Robinson, Stirtzinger, Stewart, \& Ralevski, 1994; Kornas-Biela, 1992).

On the other hand, the research on self-image and perception of one's situation among the parents in the postnatal period shows a prevalence of positive emotions such as pride, joy, and positive expectations about the new situation. Studies have also shown an increase of perceived self-worth of a woman - a mother who gave birth to a new life (Bielawska-Batorowicz, 1995).
For women who have experienced a child loss, the information about the risk of giving birth prematurely is associated with a lot of negative emotion (Steuden \& Szymona, 2003), and they may experience depressive reactions, troubles with mental health, or even suicidal thoughts directly after the loss (Barton-Smoczyńs$\mathrm{ka}, 2006$ ). Apart from the emotional and physical pain, a woman after a miscarriage might experience a crisis of faith regarding the purpose and meaning of her existence and the purpose of existence in general (Fernandez, Harris, \& Leschied, 2011; Gerber-Epstein, Leichtentritt, \& Banyamini, 2009; Szymańska \& Chazan, 2008; Barton-Smoczyńska, 2006; Maker \& Ogden, 2003).

Previous research has indicated that the loss of a fetus results in a crisis of faith in the purpose of life; it is detrimental to the perceived sense of security and control, reduces the perceived self-worth and leads to a belief that life is completely pointless. Even a year after the loss, $31 \%$ of women would still not have the ability to attribute any benefits or meaning to the experienced tragedy, and most of the women included in the study were experiencing a lowered sense of purpose and meaning in life. Mroczkowska (2011) has shown that women who have experienced miscarriage scored lower on the quality of life scale than the women who never had a miscarriage ( $M=28.40$ and $M=38.60$ accordingly).

\section{PARTICIPANTS AND PROCEDURE}

The current research was based on the following methods: the Gough and Heilbrun Adjective Check List (ACL, 1980) adapted to the Polish language by Zenomena Płużek, as well as Wong's Personal Meaning Profile (PMP) (1998).

The Adjective Check List (ACL) is one of the best known and most commonly used multiscale personality inventories. The method was created in the Institute of Personality Assessment and Research (IPAR) in Berkley, USA in the 1950s. It was introduced for use in Poland in 1983 by Zenomena Płużek, who adapted the Polish translation of the test. The test consists of 300 attributes listed as adjectives, serving to describe multiple aspects of personality. The method uses the $T$-score scoring system. Norms have been developed with a large group of subjects (4144 women and 5238 men). The accuracy and reliability of the tool has been thoroughly checked using various methods (Gough \& Heilbrun, 1980). The internal consistency tests were used to indicate the internal consistency coefficients of between $\alpha=.56$ for Cha and Suc scales and $\alpha=.95$ for the Fav scale (Juros \& Oleś, 1993).

The Adjective Check List has been adapted for the current study in order to retrospectively characterize women during pregnancy (me, during pregnancy -
Psychological changes in women after losing a child before birth 
Table 1

Clinical variables of women who lost their child (LCh)

\begin{tabular}{lcc}
\hline \multicolumn{1}{c}{ Variable } & $N$ & $\%$ \\
\hline The number of pregnancy & 17 & 28.30 \\
first & 28 & 46.70 \\
second & 15 & 25.00 \\
further & & \\
Reason for the child loss & 54 & 90.00 \\
miscarriage & 4 & 6.70 \\
premature birth & 1 & 1.70 \\
stillbirth & 1 & 1.70 \\
early death of a newborn & 8 & 13.30 \\
Medical diagnosis for the reason of child's & death \\
yes & 52 & 86.70 \\
no & & \\
Giving a name to the child & 39 & 65.00 \\
yes & 21 & 35.00 \\
no & & \\
Plans for future pregnancy & & \\
yes & & \\
no & & \\
\hline
\end{tabular}

"What were you like during pregnancy?"), as well as presently - at the time of the study after having or losing the child (me, now - "What are you like right now?"). This has allowed the comparison of women who had their child with women who experienced a loss, as well as to analyse the changes after the experienced pregnancy.

The Personal Meaning Profile questionnaire by Wong (1998) was used to measure the perceived sense of purpose and meaning in life, through highlighting potential sources and reasons for the purpose and meaning in life of a given person. The test was translated and adapted to Polish by Krok (2009). It contains 57 statements that make up 7 dimensions of the personal meaning profile: achievement, relationship, religion, self-transcendence, self-acceptance, intimacy, fair treatment. The Cronbach internal consistency of the test across the 7 dimensions using the original scale is as follows: $\alpha=.91$ for achievement, $\alpha=.81$ for relations, $\alpha=.89$ for religion, $\alpha=.84$ for self-transcendence, $\alpha=.78$ for intimacy and $\alpha=.54$ for fair treatment. For the purpose of the study, the results have been recalculated as centiles and sten scores.

The current study investigated a group of women who either had a child, or lost a child within the 3 years of the time of taking the test. The subjects were questioned in 2012 and 2013 in Lublin (Poland) and in the St. Alexander Hospital in Kielce (Poland). A total of 140 women were tested. One hundred twenty-five subjects answered all of the questions, 65 of whom had a child, and 60 lost a child.

\section{RESULTS}

The results have been divided into two groups: HCh (for Had the Child) and LCh (for Lost the Child). The mean age for both groups was 30 years. $46.70 \%$ of women in the LCh group lost their child during their second pregnancy, $28.30 \%$ during their first pregnancy and $25.00 \%$ during a further pregnancy. $90.00 \%$ of the losses were medically qualified as a miscarriage. In 52 of the cases, the reason for the death of the child was not diagnosed. $65.00 \%$ of the parents decided to give their lost child a name (Table 1).

The presented scheme visualises the relationships investigated using the ACL test. The perceived self-image was investigated in two groups, in retrospect and at present (Figure 1).

The comparison between $\mathrm{HCh}$ and LCh retrospective accounts of the pregnancy revealed no significant differences, whereas the current perceived self-images of both groups were significantly different in many aspects (Table 2).

The women who lost a child (LCh) had a tendency towards lower scores for number of checked adjectives (No Ckd), number of favourable adjectives (Fav) and communality (Com). As well as that, their need for achievement (Ach), need for dominance (Dom), need for endurance (End) and need for order (Ord), need for intraception (Int), need to nurture others (Nur), need for affiliation (Aff), need for interaction with opposite-sex partners (Het) and the need to exhibit oneself (Exh) were all lower. Additionally, they exhibited a lower self-confidence (S-Cfd), personal adjustment (P-Adj), scale of the ideal self (Iss), a tendency in the scale of creative personality (Cps), lower scores on the military leader scale (Mls) and masculinity scale (Mas), and a tendency on the femininity scale (Fem). In terms of the transactional analysis they scored lower in the subscales of nurturing parent (NP), adult (A) and free child (FC). In the Origence-Intelligence scale they scored lower in A3 (low origence - low intelligence) and A-4 (low origence high intelligence). The investigated LCh women had higher scores in the overall number of unfavourable adjectives (Unfav), in the need for autonomy (Aut) and in the need of self-abasement (Aba). Their results in the transactional analysis subscale were lower for adapted child (AC) and in the A-1 dimension - that is high origence and low intelligence.

The highest mean scores (over 50) for the $\mathrm{HCh}$ group were observed in the need for aggression (Agg), on the critical parent (CP) and adapted child 


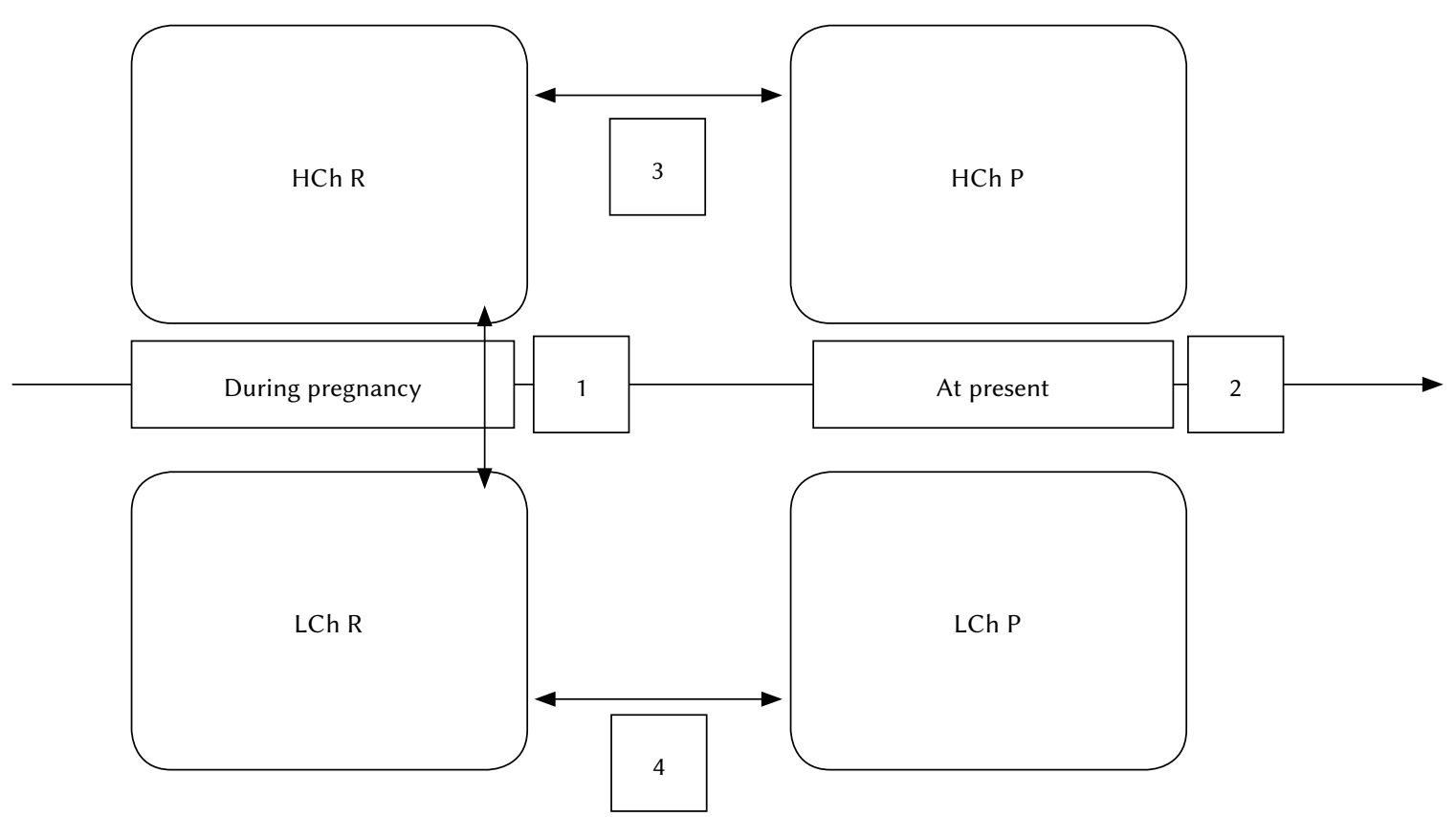

Psychological changes in women after losing a child before birth

Figure 1. The choice of groups in order to investigate significant differences in the within and between group model.

(AC) scales, the need for exhibition (Exh) and the need for support from others (Suc). One of the low scores in this group referred to the need to nurture others (Nur).

In the group of women who lost their child, the highest mean scores were for the total number of unfavourable adjectives (Unfav $=60.45)$ as well as on the adapted child scale $(\mathrm{AC}=60.60)$. High scores (above 50) were observed for the need of self-abasement $($ Aba $=57.88)$, the need for autonomy (Aut $=52.68)$, the need for aggression $(\mathrm{Agg}=54.58)$, the need for support from others (Suc $=52.57)$ and critical parent $(\mathrm{CP}=52.00)$. The lowest mean score in this group was for the need for affiliation (Aff $=30.13$ ). Figure 2 illustrates the mean scores for self-image on the given subscales in $\mathrm{HCh}$ and LCh groups.

Upon investigating the differences between the LCh and HCh groups' self-image both in retrospect and at present, a comparative analysis was conducted between the self-image of $\mathrm{HCh}$ in retrospect and at present. Significant differences were observed, where the HCh women had higher scores at retrospect for the need for interaction with the opposite sex (Het) and adapted child (AC). The scores for need for dominance (Dom), endurance (End) and order (Ord) were higher in the current self-image. There was also a tendency towards higher scores for the need of intraception (Int) and on the ideal self scale. The transactional analysis revealed a tendency for higher scores in critical parent $(\mathrm{CP})$, nourishing parent (NP), adult (A) scales and the A-4 dimension (low origence - high intelligence). The relations between the means are summarized in Table 3.
Significant changes were observed when comparing the retrospective and the present self-image of women who have had the child. The scores were higher for the retrospective accounts for the need for interactions with the opposite sex (Het), and on the adapted child scale (AC).

On the other hand, scores for the need for dominance (Dom), endurance (End), and order (Ord) were higher for the present assessment. There was also a tendency towards higher scores for the need to understand oneself and others (Int), and the ideal self scale (Iss). The transactional analysis revealed a tendency toward higher scores for the critical parent $(\mathrm{CP})$, nourishing parent $(\mathrm{NP})$ and adult $(\mathrm{A})$ scales, as well as the A-4 dimension (low origence - high intelligence), as presented in Table 4.

The direction of significant differences between means is contained in the summary of the self-image data in Table 5 (Figure 3).

The within-group comparison for women who had lost their child (LCh) is presented below (Table 4).

The comparison of retrospective and present accounts of self-image of women who had lost their child revealed some significant differences. These women scored higher in retrospect for the number of favourable adjectives (Fav), Communality (Com), the need for achievement (Ach), the need for dominance (Dom), the need for endurance (End), the need for order (Ord), the need to understand oneself and others (Int), the need to nurture others (Nur), the need for affiliation (Aff), the need for interaction with the opposite sex (Het), the need for exhibition (Exh), the need for change (Cha), self-confidence (S-Cfd), personal adjustment (P-Adj), the ideal self scale (Iss), 
Table 2

Mean scores, standard deviation and differences between the current self-image of HCh and LCh women in the ACL test

\begin{tabular}{|c|c|c|c|c|c|c|}
\hline \multirow{2}{*}{ Variable } & \multicolumn{2}{|c|}{$\mathrm{HCh}(n=65)$} & \multicolumn{2}{|c|}{$\operatorname{LCh}(n=60)$} & \multirow{2}{*}{$t$} & \multirow{2}{*}{$p$} \\
\hline & $M$ & $S D$ & $M$ & $S D$ & & \\
\hline Total number of checked adjectives (No Ckd) & 34.05 & 8.14 & 31.45 & 7.41 & 1.86 & .065 \\
\hline Number of favourable adjectives (Fav) & 39.14 & 9.83 & 30.95 & 8.52 & 4.96 & .001 \\
\hline Number of unfavourable adjectives (Unfav) & 49.37 & 9.22 & 60.45 & 12.47 & -5.68 & .001 \\
\hline Communality (Com) & 33.75 & 6.47 & 28.73 & 6.71 & 4.26 & .001 \\
\hline The need for achievement (Ach) & 47.03 & 8.63 & 39.92 & 6.99 & 5.04 & .001 \\
\hline The need for dominance (Dom) & 50.92 & 7.72 & 43.62 & 9.00 & 4.88 & .001 \\
\hline The need for endurance (End) & 49.23 & 10.64 & 40.12 & 10.36 & 4.85 & .001 \\
\hline The need for order (Ord) & 51.34 & 8.80 & 43.17 & 9.54 & 4.98 & .001 \\
\hline The need to understand oneself and others (Int) & 42.48 & 8.04 & 36.20 & 8.55 & 4.23 & .001 \\
\hline The need to take care of others (Nur) & 40.83 & 7.56 & 36.12 & 8.41 & 3.30 & .001 \\
\hline The need for affiliation (Aff) & 38.77 & 10.25 & 30.13 & 9.89 & 4.78 & .001 \\
\hline The need to interact with the opposite sex (Het) & 43.08 & 9.50 & 34.48 & 11.78 & 4.51 & .001 \\
\hline The need to exhibit oneself (Exh) & 51.68 & 6.18 & 47.68 & 7.26 & 3.32 & .001 \\
\hline The need for autonomy (Aut) & 50.03 & 5.55 & 52.68 & 7.63 & -2.24 & .027 \\
\hline The need for aggression (Agg) & 53.86 & 7.10 & 54.58 & 6.97 & -0.57 & .568 \\
\hline The need for change (Cha) & 42.63 & 6.48 & 41.20 & 5.41 & 1.33 & .185 \\
\hline The need for support from others (Suc) & 51.08 & 7.17 & 52.57 & 7.84 & -1.11 & .269 \\
\hline The need for self-abasement (Aba) & 50.38 & 6.40 & 57.88 & 9.97 & -5.04 & .001 \\
\hline The need to subordinate to others (Def) & 48.17 & 5.94 & 48.20 & 6.11 & -0.03 & .977 \\
\hline The readiness for counselling $(\mathrm{Crs})$ & 48.11 & 8.20 & 50.37 & 8.90 & -1.48 & .142 \\
\hline Self-control (S-Cn) & 48.97 & 6.62 & 47.55 & 6.26 & 1.23 & .222 \\
\hline Self-confidence (S-Cfd) & 48.98 & 9.36 & 39.48 & 9.96 & 5.50 & .001 \\
\hline Personal adjustment (P-Adj) & 44.37 & 7.96 & 37.07 & 7.56 & 5.25 & .001 \\
\hline The idea self scale (Iss) & 51.77 & 11.70 & 42.20 & 9.34 & 5.03 & .001 \\
\hline Creative personality scale (Cps) & 48.26 & 8.01 & 46.23 & 4.30 & 1.74 & .084 \\
\hline Military leader scale (MIs) & 42.71 & 8.62 & 37.02 & 7.62 & 3.90 & .001 \\
\hline Masculinity scale (Mas) & 49.35 & 8.93 & 44.27 & 7.41 & 3.45 & .001 \\
\hline Femininity scale (Fem) & 41.72 & 9.20 & 38.93 & 6.81 & 1.91 & .058 \\
\hline Critical parent $(\mathrm{CP})$ & 52.68 & 7.16 & 52.00 & 6.66 & 0.55 & .586 \\
\hline Nurturing parent (NP) & 45.31 & 8.49 & 39.23 & 8.40 & 4.02 & .001 \\
\hline Adult (A) & 47.05 & 7.63 & 40.90 & 7.82 & 4.45 & .001 \\
\hline Free child (FC) & 46.49 & 6.27 & 41.10 & 7.25 & 4.46 & .001 \\
\hline Adapted child (AC) & 52.38 & 7.78 & 60.60 & 7.85 & -5.87 & .001 \\
\hline High origence - low intelligence (A-1) & 43.57 & 6.52 & 46.42 & 8.05 & -2.18 & .031 \\
\hline High origence - high intelligence (A-2) & 45.37 & 6.80 & 45.75 & 7.01 & -0.31 & .758 \\
\hline Low origence - low intelligence (A-3) & 44.77 & 9.91 & 39.32 & 8.78 & 3.25 & .002 \\
\hline Low origence - high intelligence (A-4) & 47.46 & 8.21 & 40.68 & 6.95 & 4.96 & .001 \\
\hline
\end{tabular}




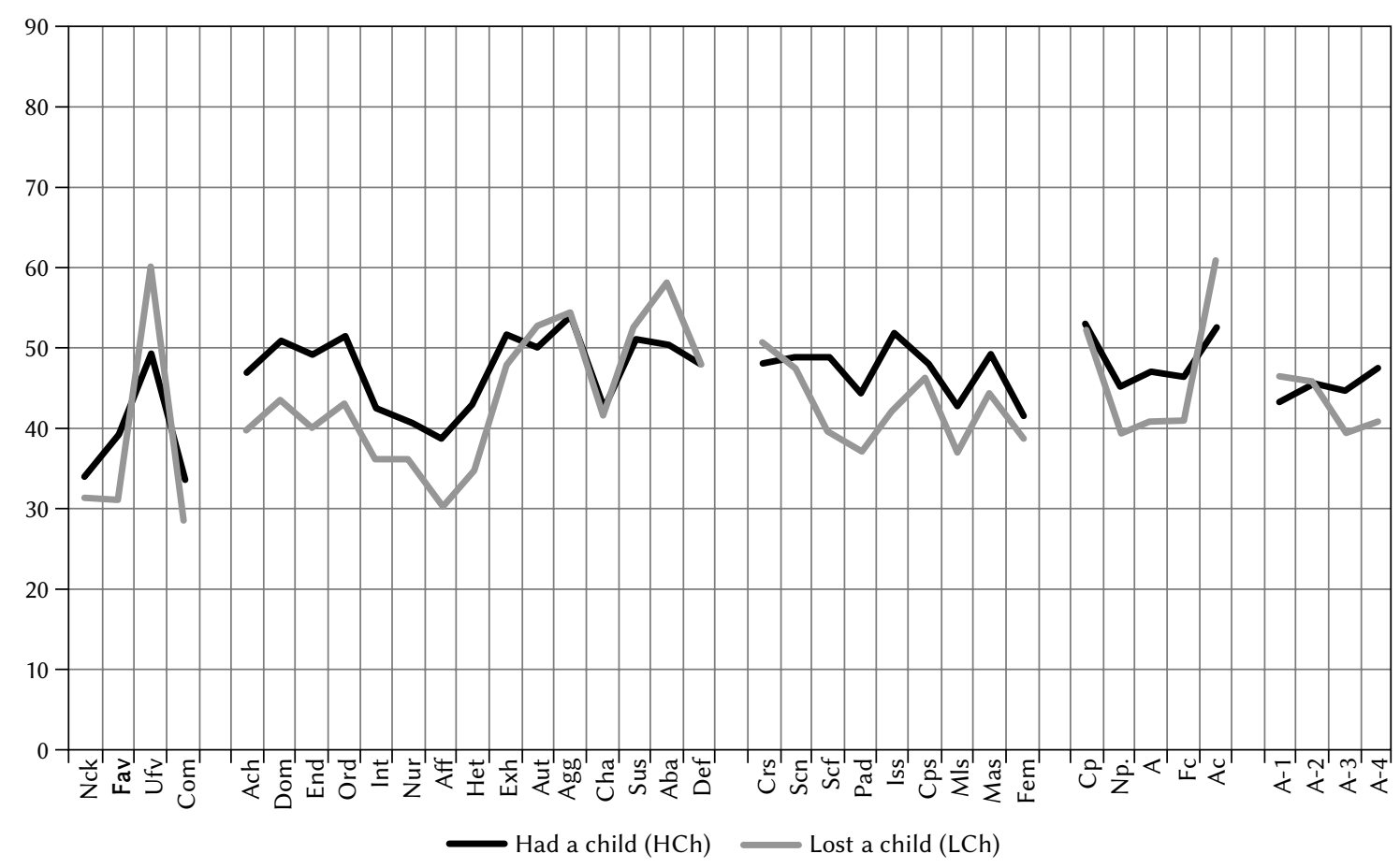

Psychological changes in women after losing a child before birth

Figure 2. Mean scores for the current self-image of women who had their child (HCh) and lost their child (LCh).

creative personality (Cps), military leader scale (Mls), femininity scale (Fem), three of the transactional analysis scales (NP, A, FC) and two of the Welsch's intelligence dimensions (A-1, A-2).

At present they scored higher for the number of unfavourable adjectives (Unfav), the need for autonomy (Aut), the readiness for counselling ( $\mathrm{Crs}$ ) and the adapted child scale (AC) as well as two of the Welsch intelligence dimensions (A-3, A-4).

The highest mean scores for the retrospective self-image were observed on the adapted child scale (AC), the need for aggression (Agg) and the need for to exhibit oneself (Exh). The highest scores for the present self-image were also obtained on the adapted child scale $(A C=60.60)$, the need for aggression (Agg) as well as the need for self-abasement (Aba). Figure 4 shows within-group differences between the means.

All of the above is presented in a form of a table describing the significant differences between women who had the child (HCh), women who lost the child (LCh) during pregnancy as well as a within-group comparison between the retrospective and present self-images of both groups of women. The results were compared four-ways and all of the results with significant differences, and the directions of these differences are presented in Table 5.

The comparison between the groups during pregnancy revealed three significant differences: the $\mathrm{HCh}$ group scored lower on the unfavourable adjectives, communality (Com) and the A-2 dimension. Comparing the present accounts of the two groups re- garding the time after the pregnancy, reveals a large number of differences. Women who lost their child scored lower on Fav, Com, Ach, Dom, End, Ord, Int, Aff, Het, S-Cfd, P-Adj, Iss, Mls, Mas, NP, A, FC, A-3 and A-4 scales. These scales are associated with aspirations, self-development and positive self-description. Moreover, the LCh group scored higher, and the mean score was statistically different to that of the HCh women on the Unfav, Aut, Aba and A-1 scales.

The within-group comparison of self-image reveals a larger number of significantly different means in the LCh group. The ratio of HCh: LCh differences equals 11 statistically significant differences (including 4 tendencies) to 31 statistically significant differences. The group of women who had the child scored higher in the need for dominance (Dom), the need for endurance (End), need for order (Ord), the Adult (A) scale and the A-4 dimension when answering the questions about the period after giving birth. However, they scored lower when answering about their present need for interaction with the opposite sex (Het), and on the adapted child scale (AC). Women who lost their child scored lower for: the number of favourable adjectives (Fav), Communality (Com), need for achievement (Ach), need for dominance (Dom), need for endurance (End), need for order (Ord), need for intraception (Int), the need to nurture others (Nur), need for affiliation (Aff), need for interactions with the opposite sex (Het), need for exhibition (Exh), and need for change (Cha); and on the scales of self-confdence (S-Cfd), personal adjustment (P-Adj), ideal self (Iss), creative personality (Cps), military leader (Mls), 
Table 3

Mean scores, standard deviation and differences between the retrospective and present self-image in the HCh group, according to the ACL test

\begin{tabular}{|c|c|c|c|c|c|c|}
\hline \multirow[t]{2}{*}{ Variable } & \multicolumn{2}{|c|}{$\begin{array}{l}\text { At the time } \\
\text { of pregnancy }\end{array}$} & \multicolumn{2}{|c|}{ At present } & \multirow[t]{2}{*}{$t$} & \multirow[t]{2}{*}{$p$} \\
\hline & $M$ & $S D$ & M & $S D$ & & \\
\hline Total number of checked adjectives (No Ckd) & 33.37 & 6.75 & 34.05 & 8.14 & -1.34 & .185 \\
\hline Number of favourable adjectives (Fav) & 38.18 & 9.00 & 39.14 & 9.83 & -0.82 & .413 \\
\hline Number of unfavourable adjectives (Unfav) & 51.17 & 9.98 & 49.37 & 9.22 & 1.25 & .217 \\
\hline Communality (Com) & 34.14 & 7.34 & 33.75 & 6.47 & 0.39 & .696 \\
\hline The need for achievement (Ach) & 45.20 & 8.43 & 47.03 & 8.63 & -1.61 & .113 \\
\hline The need for dominance (Dom) & 47.55 & 7.29 & 50.92 & 7.72 & -2.93 & .005 \\
\hline The need for endurance (End) & 45.51 & 9.40 & 49.23 & 10.64 & -2.62 & .011 \\
\hline The need for order (Ord) & 48.09 & 7.86 & 51.34 & 8.80 & -2.75 & .008 \\
\hline The need to understand oneself and others (Int) & 40.71 & 6.32 & 42.48 & 8.04 & -1.72 & .090 \\
\hline The need to take care of others (Nur) & 41.17 & 7.46 & 40.83 & 7.56 & 0.33 & .743 \\
\hline The need for affiliation (Aff) & 39.89 & 11.44 & 38.77 & 10.25 & 0.85 & .400 \\
\hline The need to interact with the opposite sex (Het) & 45.69 & 9.89 & 43.08 & 9.50 & 2.15 & .035 \\
\hline The need to exhibit oneself (Exh) & 51.29 & 7.04 & 51.68 & 6.18 & -0.43 & .666 \\
\hline The need for autonomy (Aut) & 49.77 & 5.72 & 50.03 & 5.55 & -0.33 & .746 \\
\hline The need for aggression (Agg) & 52.66 & 7.35 & 53.86 & 7.12 & -1.29 & .202 \\
\hline The need for change (Cha) & 43.92 & 6.75 & 42.63 & 6.48 & 1.21 & .233 \\
\hline The need for support from others (Suc) & 52.68 & 7.23 & 51.08 & 7.17 & 1.47 & .147 \\
\hline The need for self-abasement (Aba) & 51.45 & 7.70 & 50.38 & 6.40 & 1.00 & .322 \\
\hline The need to subordinate to others (Def) & 49.34 & 5.69 & 48.17 & 5.94 & 1.37 & .176 \\
\hline The readiness for counselling ( $\mathrm{Crs}$ ) & 46.25 & 7.35 & 48.11 & 8.20 & -1.55 & .127 \\
\hline Self-control (S-Cn) & 47.75 & 5.43 & 48.97 & 6.62 & -1.64 & .105 \\
\hline Self-confidence (S-Cfd) & 47.40 & 9.68 & 48.98 & 9.36 & -1.29 & .201 \\
\hline Personal adjustment (P-Adj) & 42.83 & 7.88 & 44.37 & 7.96 & -1.33 & .189 \\
\hline The idea self scale (Iss) & 48.66 & 11.40 & 51.77 & 11.70 & -1.92 & .059 \\
\hline Creative personality scale (Cps) & 48.80 & 8.02 & 48.26 & 8.01 & 0.42 & .678 \\
\hline Military leader scale (MIs) & 42.11 & 6.78 & 42.71 & 8.62 & -0.49 & .624 \\
\hline Masculinity scale (Mas) & 47.54 & 8.53 & 49.35 & 8.93 & -1.46 & .149 \\
\hline Femininity scale (Fem) & 42.23 & 8.42 & 41.72 & 9.20 & 0.50 & .617 \\
\hline Critical parent $(\mathrm{CP})$ & 50.35 & 9.90 & 52.68 & 7.16 & -1.86 & .068 \\
\hline Nurturing parent (NP) & 42.65 & 7.85 & 45.31 & 8.49 & -1.94 & .057 \\
\hline Adult (A) & 44.35 & 6.59 & 47.05 & 7.63 & -2.45 & .017 \\
\hline Free child (FC) & 47.29 & 7.03 & 46.49 & 6.27 & 0.83 & .410 \\
\hline Adapted child (AC) & 55.98 & 7.18 & 52.38 & 7.78 & 3.23 & .002 \\
\hline High origence - low intelligence (A-1) & 44.38 & 7.67 & 43.57 & 6.52 & 0.71 & .480 \\
\hline High origence - high intelligence $(A-2)$ & 46.18 & 6.18 & 45.37 & 6.80 & 0.87 & .389 \\
\hline Low origence - low intelligence (A-3) & 46.02 & 9.46 & 44.77 & 9.91 & 0.97 & .335 \\
\hline Low origence - high intelligence $(\mathrm{A}-4)$ & 44.55 & 7.82 & 47.46 & 8.21 & -2.37 & .021 \\
\hline
\end{tabular}


Table 4

Mean scores, standard deviation and differences between the retrospective and present self-image in the LCh group, according to the ACL test

\begin{tabular}{|c|c|c|c|c|c|c|}
\hline \multirow[t]{2}{*}{ Variable } & \multicolumn{2}{|c|}{$\begin{array}{l}\text { At the time } \\
\text { of pregnancy }\end{array}$} & \multicolumn{2}{|c|}{ At present } & \multirow[t]{2}{*}{$t$} & \multirow[t]{2}{*}{$p$} \\
\hline & $M$ & $S D$ & $M$ & $S D$ & & \\
\hline Total number of checked adjectives (No Ckd) & 32.02 & 6.90 & 31.45 & 7.41 & 1.48 & .146 \\
\hline Number of favourable adjectives (Fav) & 37.68 & 7.55 & 30.95 & 8.52 & 5.41 & .001 \\
\hline Number of unfavourable adjectives (Unfav) & 45.83 & 6.31 & 60.45 & 12.47 & -7.87 & .001 \\
\hline Communality (Com) & 31.60 & 6.39 & 28.73 & 6.71 & 2.35 & .022 \\
\hline The need for achievement (Ach) & 47.10 & 6.10 & 39.92 & 6.99 & 5.75 & .001 \\
\hline The need for dominance (Dom) & 49.03 & 7.81 & 43.62 & 9.00 & 4.05 & .001 \\
\hline The need for endurance (End) & 46.95 & 8.18 & 40.12 & 10.36 & 4.56 & .001 \\
\hline The need for order (Ord) & 49.65 & 7.30 & 43.17 & 9.54 & 4.41 & .001 \\
\hline The need to understand oneself and others (Int) & 40.55 & 5.98 & 36.20 & 8.55 & 3.68 & .001 \\
\hline The need to take care of others (Nur) & 42.37 & 6.55 & 36.12 & 8.41 & 5.70 & .001 \\
\hline The need for affiliation (Aff) & 39.98 & 10.56 & 30.13 & 9.89 & 6.48 & .001 \\
\hline The need to interact with the opposite sex (Het) & 46.73 & 8.88 & 34.48 & 11.78 & 6.64 & .001 \\
\hline The need to exhibit oneself (Exh) & 53.43 & 6.23 & 47.68 & 7.26 & 4.68 & .001 \\
\hline The need for autonomy (Aut) & 49.30 & 6.19 & 52.68 & 7.63 & -3.01 & .004 \\
\hline The need for aggression (Agg) & 53.82 & 7.47 & 54.58 & 6.97 & -0.72 & .474 \\
\hline The need for change (Cha) & 42.97 & 5.44 & 41.20 & 5.41 & 2.12 & .038 \\
\hline The need for support from others (Suc) & 50.63 & 8.14 & 52.57 & 7.84 & -1.66 & .103 \\
\hline The need for self-abasement (Aba) & 50.78 & 8.53 & 57.88 & 9.97 & -4.47 & .001 \\
\hline The need to subordinate to others (Def) & 49.18 & 6.23 & 48.20 & 6.11 & 1.13 & .265 \\
\hline The readiness for counselling $(\mathrm{Crs})$ & 46.33 & 8.01 & 50.37 & 8.90 & -3.07 & .003 \\
\hline Self-control (S-Cn) & 48.15 & 5.70 & 47.55 & 6.26 & 0.67 & .505 \\
\hline Self-confidence (S-Cfd) & 48.77 & 9.37 & 39.48 & 9.96 & 5.35 & .001 \\
\hline Personal adjustment (P-Adj) & 42.65 & 7.00 & 37.07 & 7.56 & 4.56 & .001 \\
\hline The idea self scale (Iss) & 48.85 & 7.83 & 42.20 & 9.34 & 4.15 & .001 \\
\hline Creative personality scale (Cps) & 48.88 & 6.59 & 46.23 & 4.30 & 2.85 & .006 \\
\hline Military leader scale (MIs) & 41.85 & 5.86 & 37.02 & 7.62 & 4.32 & .001 \\
\hline Masculinity scale (Mas) & 46.62 & 8.36 & 44.27 & 7.41 & 1.67 & .101 \\
\hline Femininity scale (Fem) & 44.42 & 7.41 & 38.93 & 6.81 & 4.92 & .001 \\
\hline Critical parent $(\mathrm{CP})$ & 47.98 & 8.39 & 52.00 & 6.66 & -3.45 & .001 \\
\hline Nurturing parent (NP) & 44.43 & 7.83 & 39.23 & 8.40 & 3.78 & .001 \\
\hline Adult (A) & 44.82 & 6.53 & 40.90 & 7.82 & 3.33 & .001 \\
\hline Free child (FC) & 48.77 & 6.40 & 41.10 & 7.25 & 5.81 & .001 \\
\hline Adapted child (AC) & 55.83 & 6.20 & 60.60 & 7.85 & -3.86 & .001 \\
\hline High origence - low intelligence $(A-1)$ & 43.50 & 6.60 & 46.42 & 8.05 & -2.49 & .016 \\
\hline High origence - high intelligence $(A-2)$ & 43.73 & 5.11 & 45.75 & 7.01 & -2.21 & .031 \\
\hline Low origence - low intelligence (A-3) & 47.50 & 10.20 & 39.32 & 8.78 & 6.30 & .001 \\
\hline Low origence - high intelligence $(A-4)$ & 43.90 & 6.54 & 40.68 & 6.95 & 3.06 & .003 \\
\hline
\end{tabular}

Psychological changes in women after losing a child before birth 
Table 5

Directions of the significant differences in self-image according to ACL test in the investigated groups

Monika

Guzewicz, Stanisława Steuden, Katarzyna Szymona-Pałkowska

\begin{tabular}{|c|c|c|c|c|}
\hline \multirow{2}{*}{ ACL self-image } & \multicolumn{2}{|c|}{$\begin{array}{c}\text { Comparison between } \\
\text { the groups }\end{array}$} & \multicolumn{2}{|c|}{$\begin{array}{c}\text { Changes } \\
\text { in self-image }\end{array}$} \\
\hline & $\begin{array}{l}\mathrm{HCh} \mathrm{R-} \\
\mathrm{LCh} \mathrm{R}\end{array}$ & $\begin{array}{l}\mathrm{HCh} P- \\
\text { LCh P }\end{array}$ & $\begin{array}{c}\mathrm{HCh} \mathrm{R-} \\
\text { LCh P }\end{array}$ & $\begin{array}{l}\text { LCh R - } \\
\text { LCh P }\end{array}$ \\
\hline Total number of checked adjectives (No Ckd) & & $>\mathrm{t}$ & & \\
\hline Number of favourable adjectives (Fav) & & $>* * *$ & & $>* * *$ \\
\hline Number of unfavourable adjectives (Unfav) & $>* * *$ & $<* * *$ & & $<* * *$ \\
\hline Communality (Com) & $>^{*}$ & $>^{* * *}$ & & $>^{*}$ \\
\hline The need for achievement (Ach) & & $>* * *$ & & $>* * *$ \\
\hline The need for dominance (Dom) & & $>* * *$ & $<* *$ & $>* * *$ \\
\hline The need for endurance (End) & & $>* * *$ & $<* *$ & $>* * *$ \\
\hline The need for order (Ord) & & $>* * *$ & $<* *$ & $>* * *$ \\
\hline The need to understand oneself and others (Int) & & $>* * *$ & $<\mathrm{t}$ & $>* * *$ \\
\hline The need to take care of others (Nur) & & $>* * *$ & & $>* * *$ \\
\hline The need for affiliation (Aff) & & $>* * *$ & & $>* * *$ \\
\hline The need to interact with the opposite sex (Het) & & $>* * *$ & $>^{*}$ & $>* * *$ \\
\hline The need to exhibit oneself (Exh) & & $>^{* * *}$ & & $>* * *$ \\
\hline The need for autonomy (Aut) & & $<^{*}$ & & $<* *$ \\
\hline \multicolumn{5}{|l|}{ The need for aggression (Agg) } \\
\hline The need for change (Cha) & & & & $>$ * \\
\hline \multicolumn{5}{|l|}{ The need for support from others (Suc) } \\
\hline The need for self-abasement (Aba) & & $<* * *$ & & $<* * *$ \\
\hline \multicolumn{5}{|l|}{ The need to subordinate to others (Def) } \\
\hline The readiness for counselling ( $\mathrm{Crs}$ ) & & & & $<* *$ \\
\hline \multicolumn{5}{|l|}{ Self-control (S-Cn) } \\
\hline Self-confidence (S-Cfd) & & $>* * *$ & & $>* * *$ \\
\hline Personal adjustment (P-Adj) & & $>* * *$ & & $>* * *$ \\
\hline The idea self scale (Iss) & & $>* * *$ & $>\mathrm{t}$ & $>* * *$ \\
\hline Creative personality scale (Cps) & & $>\mathrm{t}$ & & $>$ ** \\
\hline Military leader scale (Mls) & & $>* * *$ & & $>* * *$ \\
\hline Masculinity scale (Mas) & & $>* * *$ & & \\
\hline Femininity scale (Fem) & & $>\mathrm{t}$ & & $>* * *$ \\
\hline Critical parent $(\mathrm{CP})$ & & & $<\mathrm{t}$ & $<* * *$ \\
\hline Nurturing parent (NP) & & $>* * *$ & $<\mathbf{t}$ & $>* * *$ \\
\hline Adult (A) & & $>^{* * *}$ & $<*$ & $>* * *$ \\
\hline Free child (FC) & & $>* * *$ & & $>* * *$ \\
\hline Adapted child (AC) & & $<* *$ & $>^{* *}$ & $<* *$ \\
\hline High origence - low intelligence $(A-1)$ & & $<*$ & & $<*$ \\
\hline High origence - high intelligence $(A-2)$ & $>^{* *}$ & & & $<*$ \\
\hline Low origence - low intelligence (A-3) & & $>^{* *}$ & & $>* * *$ \\
\hline Low origence - high intelligence $(A-4)$ & & $>^{* * *}$ & $<*$ & $>^{* *}$ \\
\hline
\end{tabular}

Note. ${ }^{* * *}$ the correlation is significant at .001 (two-tailed); ${ }^{* *}$ the correlation is significant at .010 (two-tailed); ${ }^{*}$ the correlation is significant at 050 (two-tailed)

$\mathrm{HCh}$ - the group of women who had the child; LCh - the group of women who lost the child; R - retrospective account ("What were you like during pregnancy?"); P - present account (“What are you like now?"); symbols <, > indicate respectively increase or decrease in the given variable, $\mathrm{t}$ - a tendency towards a significant difference 


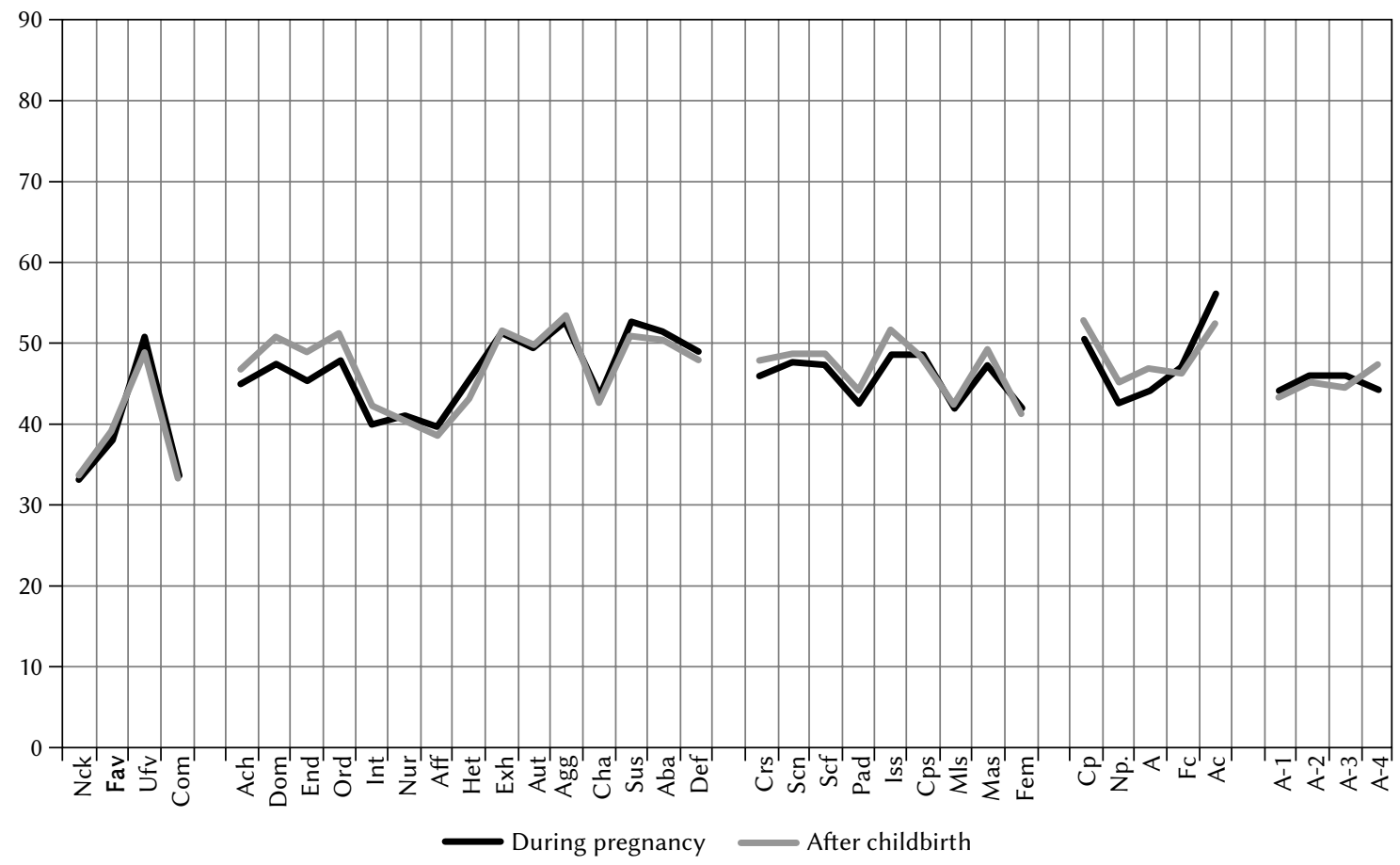

Psychological changes in women after losing a child before birth

Figure 3. Mean scores for self-image during pregnancy and after childbirth for women who had a child (HCh).

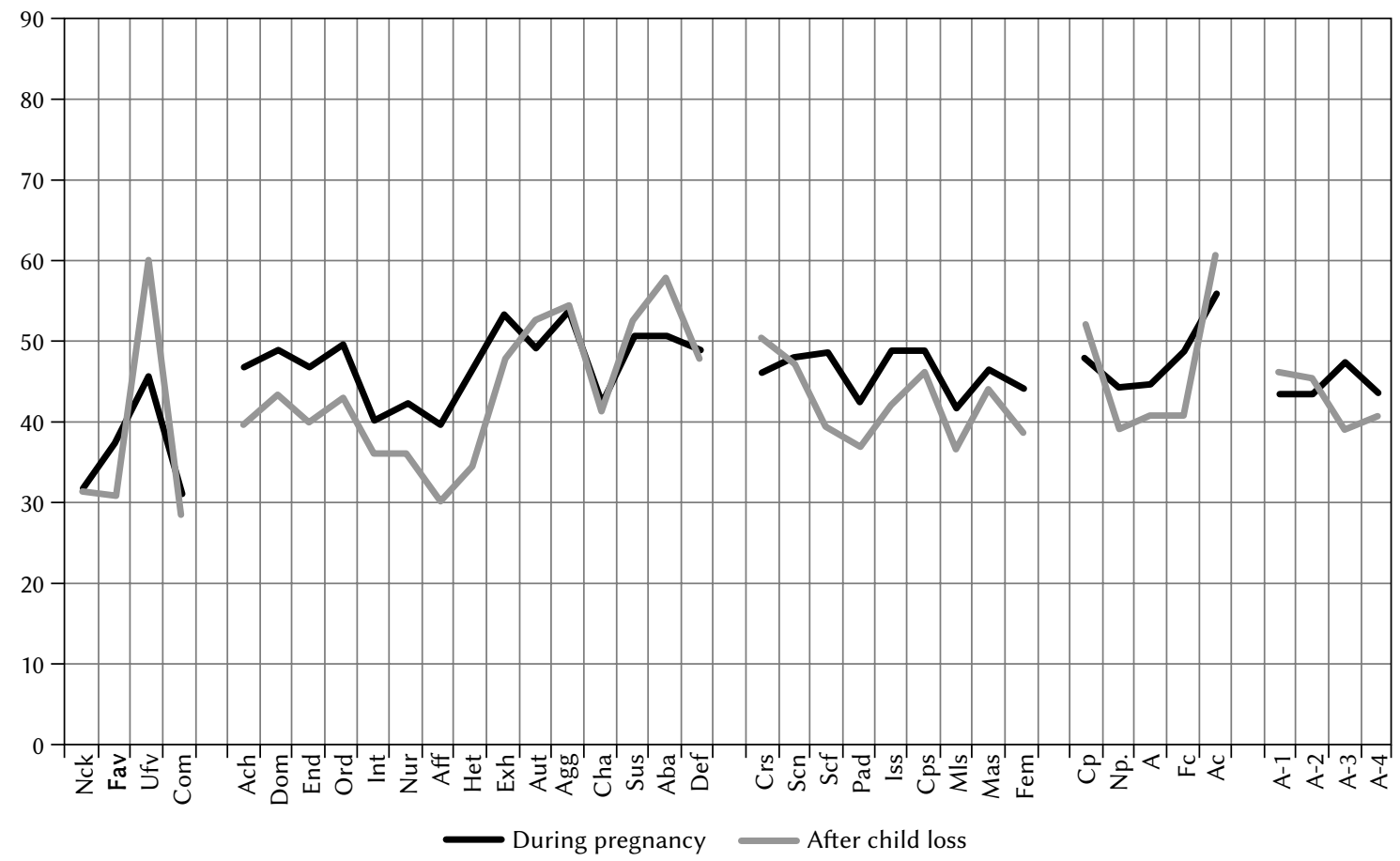

Figure 4. Mean scores for self-image during pregnancy and after child loss for women who lost a child (LCh).

and femininity (Fem), when answering questions about their present perceptions. Apart from that, lower scores were observed in three of the dimensions of the transactional analysis (NP, A, FC) as well as A-3 and A-4. Statistically significantly higher results were observed for the number of unfavourable adjectives (Unfav), the need for autonomy (Aut), the need for self-abasement (Aba), the readiness for counselling (Crs), critical parent (CP), and adapted child (AC) scales and dimensions A-1 and A-2.

The Personal Meaning Profile by Wong (1998) test was used in order to investigate the sense of purpose and meaning in life. The method includes 7 scales regarding achievement (AC), relationships (RS), re- 
Table 6

Means and standard deviations of the differences between the groups of women in the PMP test

\begin{tabular}{|c|c|c|c|c|c|c|}
\hline \multirow{2}{*}{ Variable } & \multicolumn{2}{|c|}{$\mathrm{HCh}(n=65)$} & \multicolumn{2}{|c|}{$\operatorname{LCh}(n=60)$} & \multirow{2}{*}{$t$} & \multirow{2}{*}{$p$} \\
\hline & $M$ & $S D$ & $M$ & $S D$ & & \\
\hline Achievement (AC) & 5.08 & 0.89 & 5.00 & 0.85 & 0.55 & .587 \\
\hline Relationships (RS) & 5.19 & 0.87 & 5.40 & 0.71 & -1.49 & .140 \\
\hline Religion (RL) & 5.52 & 1.02 & 4.79 & 1.26 & 3.56 & .001 \\
\hline Self-transcendence (ST) & 4.91 & 1.07 & 4.80 & 1.44 & 0.49 & .628 \\
\hline Self-acceptance (SA) & 4.91 & 1.00 & 4.56 & 0.97 & 1.96 & .052 \\
\hline Intimacy (IT) & 5.93 & 0.85 & 6.28 & 0.90 & -2.24 & .027 \\
\hline Fair treatment (FT) & 4.42 & 1.02 & 3.47 & 1.29 & 4.58 & .001 \\
\hline
\end{tabular}

Table 7

Means and standard deviations of the results of the PMP test for both groups recalculated as centiles and sten scores

\begin{tabular}{lccccccccc}
\hline & \multicolumn{4}{c}{ Centiles } & \multicolumn{5}{c}{ Sten scores } \\
\cline { 2 - 10 } \multicolumn{1}{c}{ Variable } & \multicolumn{1}{c}{$\mathrm{HCh}(n=65)$} & $\mathrm{LCh}(n=60)$ & \multicolumn{1}{c}{$\mathrm{HCh}(n=65)$} & \multicolumn{2}{c}{$\mathrm{LCh}(n=60)$} \\
\cline { 2 - 10 } & 54.34 & 28.33 & 46.40 & 28.66 & 5.60 & 1.87 & 5.30 & 2.06 \\
\hline Achievement (AC) & 46.86 & 29.18 & 54.77 & 27.87 & 5.18 & 2.02 & 5.82 & 1.81 \\
Relationships (RS) & 58.58 & 26.15 & 41.72 & 29.19 & 6.02 & 1.88 & 4.88 & 2.06 \\
Religion (RL) & 53.97 & 29.40 & 46.62 & 27.63 & 5.65 & 2.00 & 5.37 & 1.92 \\
Self-transcendence (ST) & 55.98 & 28.84 & 44.70 & 27.64 & 5.86 & 2.00 & 5.22 & 1.89 \\
Self-acceptance (SA) & 43.11 & 25.04 & 58.55 & 30.17 & 4.98 & 1.66 & 6.02 & 2.01 \\
Intimacy (IT) & 61.86 & 24.21 & 38.63 & 28.27 & 6.17 & 1.76 & 4.65 & 2.08 \\
Fair treatment (FT) & & & & & & & & \\
\hline
\end{tabular}

ligion (RL), self-transcendence (ST), self-acceptance (SA), intimacy (IT), and fair treatment (FT). An independent variable $t$-test was used in order to compare the results between the groups (Table 6).

The Personal Meaning Profile test revealed significant differences between the groups of women on four of the scales. The LCh women had a poorer attitude towards religion (RL), lower self-acceptance (SA), lower sense of fair treatment (FT) and a higher intimacy (IT) than HCh women. No differences were observed for the other three scales: achievement (AC), relationships (RL) and self-transcendence (ST) (Table 7).

The recalculated scores indicated that the $\mathrm{HCh}$ women base their perception of meaning in life mostly on fair treatment (FT $=61.86$ centile; sten score of 6.17), then as follows: religion (RL), self-acceptance (SA), achievement (AC), self-transcendence (ST), relationships (RS), while intimacy has the lowest input (IT $=43.11$ centiles or sten score of 4.98$)$.

In the group of women who lost their child (LCh) perception of sense of meaning in life seemed to be mostly based on intimacy (IT $=58.55$ centiles or a sten score of 6.02), then as follows: relationships (RS), self-transcendence (ST), achievement (AC), self-acceptance (SA), religion (RL), fair treatment $(\mathrm{FT}=38.63$ centiles or a sten score of 4.65$)$.

\section{DISCUSSION}

The comparative analysis of results revealed significant differences in terms of the self-image in both the retrospective view regarding the period of pregnancy and the present view between the studied groups of women (Table 2). The women in the HCh group assessed the time of the pregnancy in more unfavourable ways, which may be associated with the fact that in contrast to the women who lost a child (LCh) they describe the present state as better.

Women from the LCh group chose less positive adjectives when describing themselves in their current situation. They exhibited a fear for the future 
and they were overwhelmed by the events in their life (Fav). They also found it difficult to mobilise their own potential and make decisions (S-Cfd). They had a lower need to understand themselves and others as well as to take care of others (Int, Nur).

These women are anxious, tense, overwhelmed by their situation, they so not act effectively, they have low self-confidence and they subordinate to others (Dom, Aff, AC, and S-Cfd). They have a tendency for self-abasement and loss of self-confidence (Aba, Iss). They have lower endurance, stability, effectiveness, dutifulness and they are less likely to comply with the rules (Ord, End, A, Mls, A-4, Iss). They are less interested in interpersonal interactions; they are less friendly, delicate, tolerant and sensitive (Fav, NP, Int, Nur, P-Adj, Com, Aff, and A-3). They are characterized by lower levels of energy, entrepreneurship and decidedness; they are less strong willed, creatively active and engaged (Dom, S-Cfd, Ach, Mas). They have a lower need for interactions with the opposite sex (Het), they don't feel the need to share their experiences and they seek more autonomy (Exh, Aut). The above results are consistent with previous observations by Van (2012-2013), Swanson (1999), Barton-Smoczyńska (2006) and Kornas-Biela (1992, 1993).

Women who lost their child exhibited a higher discrepancy between the retrospective and present views of themselves in comparison to women who had a child. The results in the ACL test for the retrospective and present self-image were the basis for this analysis. The present and retrospective accounts of women in the $\mathrm{HCh}$ group were statistically different in only six of the dimensions, whereas for the LCh women differences were observed in 31 areas (Table 4).

The results for women who had a child (HCh) suggest that these women exhibit a need for dominance and order, they become more responsible and nurturing and their perceived self-worth increases upon entering the role of a mother. At the same time, possibly due to hormonal changes and the specificities of the postnatal period, they exhibit a lesser interest in the interaction with the opposite sex (Dom, Ord, Iss, $\mathrm{A}$, Het).

The women who lost a child before birth (LCh), as previously mentioned, exhibited some significant differences between the retrospective and the present self-image, differences which concern multiple areas of functioning. The things that influenced most the situation of loss are the abilities and actions in the lives of these women. The low-scoring variables relate to pursuit, motivation, and activity. Auto-aggressive tendencies, such as the need for self-abasement, the need for autonomy, and self-criticism are increased (Aba, Aut, CP). The women who lost a child have a negative attitude towards both themselves and others (Unfav, Int, Nur, Aff, Het, S-Cfd, P-Adj, Iss), they
Table 8

Comparison between groups - results in all the tests

$\begin{array}{ll}\text { Areas of psychosocial functioning } & \mathrm{HCh} \\ \mathrm{LCh}\end{array}$

Self-image at present (ACL)

Number of favourable adjectives (Fav)

Number of unfavourable adjectives

(Unfav)

Communality (Com)

The need for achievement (Ach)

The need for dominance (Dom)

The need for endurance (End)

The need for order (Ord)

The need to understand oneself and others (Int)

The need to take care of others (Nur)

The need for affiliation (Aff)

The need to interact with the opposite sex (Het)

The need to exhibit oneself (Exh)

The need for autonomy (Aut)

The need for self-abasement (Aba)

Self-confidence (S-Cfd)

Personal adjustment (P-Adj)

The idea self scale (Iss)

Military leader scale (MIs)

Masculinity scale (Mas)

Femininity scale (Fem)

Nurturing parent (NP)

Adult (A)

Free child (FC)

Adapted child (AC)

High origence - low intelligence (A-1)

Low origence - low intelligence $(A-3)$

Low origence - high intelligence (A-4)

Psychological changes in women after losing a child before birth

Sense of purpose and meaning (PMP)

Attitude towards religion (RL)

$>>$

Self-acceptance (SA)

$>\mathrm{t}$.

Intimacy (IT)

$<$

Fair treatment (FT)

Note Symbols <, > refer to accordingly bigger $<$ or smaller $>$ intensity of the investigated variable; $\ll<$ difference is significant at $p \leq .001 ;<$ difference is significant at $p \leq .010$; $<$ difference is significant at $p \leq .050$ 
exhibit features that preclude their proper functioning (End, Ord, Cps, Mls), they tend to be resigned, and show a lower degree of motivation and goal-orientation (Ach, Dom, Fem). This is confirmed by the literature (Barton-Smoczyńska, 2006; Bielawska-Batorowicz, 1995; Kornas-Biela, 1992), which described an increase in the perceived self-worth of women who became mothers, and a decrease in psychosocial functioning, decrease of assets, and withdrawal together with an increase in negative emotions and opinions about themselves in women who lost their child during pregnancy.

The perceived sense of purpose and meaning in life has been investigated using Wong's PMP questionnaire, which involves 7 scales. Four of them (SR, BE, UT, SA) revealed statistically significant differences between the groups, whereas the remaining three (OS, RI, ST) did not (Table 6).

Women who lost their child tend to have negative beliefs about the relation with spirituality and God (RL). It is most probably a result of blaming God for the loss, and perceiving it as God's punishment for sins and a sign of clear existential injustice in the world. This is confirmed in the opinions of Kornas-Biela (1999), Steuden, and Szymona (2003). Moreover, these women, while searching for support, exhibit a need for intimacy (IT). According to the literature, these needs are usually fulfilled through the interactions with a partner or husband (Lachelin, 1998; Kornas-Biela, 1999) as well as contact with medical personnel who understand the situation of loss and therefore reduce the levels of sadness and sorrow (Cacciatore, Erlandsson, \& Radestad, 2013; Rinehart \& Kicelica, 2010; Abbound \& Liamputtong, 2005). The sense of support from others is an indication of greater chances for an appropriate course of grief after the loss of a child (Evans, 2012; Conry \& Prinsloo, 2008; Gerber-Epstein et al., 2009; Säflund, Sjögren, \& Wredling, 2004). These women have a sense of injustice, towards themselves and their child (UT). Their sense of justice in life is shaken - they feel treated unfairly and wrongfully. Apart from that their self-acceptance (SA) is lowered, which makes it difficult for them to draw valuable conclusions from the loss of the child, and lowers the ability to judge themselves objectively without the need to self-blame.

The biggest indicator of the perceived sense of meaning and purpose in life in the group of women who had a child was fair treatment (FT), followed by their attitude towards religion (RL), self-acceptance (SA), achievement (AC), self-transcendence (ST), and relationships (RS), with intimacy (IT) at the end of the list. A different sequence of variables influencing the sense of meaning and purpose in life was observed for the women who lost their unborn child. For these women the most important factor was intimacy (IT), followed by relationships (RS), self-transcendence (ST), achievement (AC), self-acceptance (SA), attitude to- wards religion (RL) and finally fair treatment (FT). This means that the birth of a child strengthens the sense of justice and control and deepens their spiritual lives. The loss of a child, on the other hand, generates the need for social support and close relations with other people.

Concluding the considerations about the differences between the two investigated groups of subjects, those who had a child and those who lost one, it is possible to infer that similar differences occur in the greater population. The collected results could help both professionals working with women directly after their loss of a child and at later times as well as people from their close family who are often helpless in the face of the behaviours and reactions of mothers after the loss of an unborn child. Table 8 summarizes the most important data gathered in the current study.

The most important results of the current study suggest that the women after a loss of an unborn child are characterized by a lowering of the needs and behaviours associated with personal development, and a lowered sense of purpose and meaning in life. They use mostly unfavourable adjectives while describing themselves and avoiding favourable terms. They withdraw from engagements or goal-oriented behaviours, they lose self-confidence and they take care about others with reluctance, maybe even fear. They do not like to talk about their experiences, as they lack the understanding of processes going on within themselves. Their behaviour changes, they become anxious, they withdraw from spontaneous activity. They feel betrayed by God, they seek the blame in themselves, and they perceive the loss of the child as a punishment.

\section{References}

Abbound, L., \& Liamputtong, P. (2005). When pregnancy fails: coping strategies, support networks and experiences with health care of ethnic women and their partners. Journal of Reproductive and Infant Psychology, 23, 3-18.

Barton-Smoczyńska, I. (2006). O dziecku, które odwrócito się na pięcie [About a child who turned on it's heel]. Łomianki: NAF.

Bielawska-Batorowicz, E. (1995). Determinanty spostrzegania dziecka przez rodziców w okresie poporodowym [The determinants of parents' perception of their child in the postnatal period]. Łódź: Wydawnictwo Uniwersytetu Łódzkiego.

Cacciatore, J., Erlandsson, K., \& Radestad, I. (2013). Fatherhood and suffering: A qualitative exploration of Swedish men's experiences of care after the death of a baby. International Journal of Nursing Studies, 50, 664-670. 
Conry, J., \& Prinsloo, C. (2008). Mothers' access to supportive hospital services after the loos of a baby through stillbirth or neonatal death. Health SA Gesondheid, 13, 14-24.

Evans, R. (2012). Emotional care for women who experience miscarriage. Nursing Standard, 26, 35-41.

Fernandez, R., Harris, D., \& Leschied, A. (2011). Understanding grief following pregnancy loss: a retrospective analysis regarding women's coping responses. Illness, Crisis \& Loss, 19, 143-163.

Gerber-Epstein, P., Leichtentritt, R. D., \& Banyamini, Y. (2009). The experience of miscarriage in first pregnancy: the women's voices. Death Studies, 33, 1-29.

Gough, H. G., \& Heilbrun, A. B. (1980). The Adjective Check List: Manual. Palu Alto: Consulting Psychologists Press.

Juros, A., \& Oleś, P. (1993). Struktura czynnikowa i skupieniowa Testu Przymiotnikowego ACL H.G. Gougha i A.B. Heilbruna [The factor and focus structure of the Adjective Check List test by H.G Gough and A.B. Heilbrun]. In: J. Brzeziński, \& E. Hornowska (eds.), Z psychometrycznych problemów diagnostyki psychologicznej [Psychometric problems in psychological diagnostics] (pp. 171-201). Poznań: Wydawnictwo Naukowe Uniwersytetu im. A. Mickiewicza.

Kornas-Biela, D. (1992). Potrzeby rodziców po stracie dziecka w okresie okołoporodowym. In: E. Bielawska-Batorowicz, \& D. Kornas-Biela (ed.), Z zagadnień psychologii prokreacyjnej [Issues in procreational psychology] (pp. 61-75). Lublin: Redakcja Wydawnictw KUL.

Kornas-Biela, D. (1993). Wokót początku życia ludzkiego [About the beginning of a human life]. Warszawa: Nasza Księgarnia.

Kornas-Biela, D. (ed.). (1999). Oblicza macierzyństwa [The many faces of motherhood]. Lublin: Redakcja Wydawnictw KUL.

Krok, D. (2009). Religijność a jakość życia w perspektywie mediatorów psychospotecznych [Religiosity and quality of life in the context of psychosocial mediators]. Opole: Wydawnictwo Wydziału Teologicznego UO.

Lachelin, C. G. (1998). Poronienia [Miscarriages]. Warszawa: Prószyński i S-ka.

Maker, C., \& Ogden, J. (2003). The miscarriage experience: more than just a trigger to psychological morbidity? Psychology \& Health, 18, 403-415.

Mroczkowska, D. (2011). Jakość życia kobiet po poronieniu ciąży [Womens' quality of life after miscarriage]. Życie i Ptodność, 4, 77-88.

Rinehart, M. S., \& Kicelica, M. S. (2010). Helping men with the trauma of miscarriage. Psychotherapy Theory, Research, Practice, Training, 47, 288-295.

Robinson, G. E., Stirtzinger, R., Stewart, D. E., \& Ralevski, E. (1994). Psychological reactions in women followed for 1 year after miscarriage. Journal of Reproductive and Infant Psychology, 12, 31-36.
Säflund, K., Sjögren, B., \& Wredling, R. (2004). The role of caregivers after a stillbirth: Views and experiences of parents. Birth, 31, 132-137.

Steuden, S., \& Szymona, K. (2003). Doświadczenia macierzyństwa i ojcostwa przez rodziców w sytuacji ciąży wysokiego ryzyka. In: J. Janicka, \& T. Rostowska (ed.), Psychologia w stużbie rodziny [Psychology in the service of families] (pp. 228-244). Łódź: Wydawnictwo Uniwersytetu Łódzkiego.

Swanson, K. M. (1999). Contexts and Evolution of Women's Responses to Miscarriage during the First Year after Loss. Nursing Research, 48, 288-298.

Szymańska, M., \& Chazan, B. (2008). Differences between behaviours of female patients from Poland and Belarussia after natural miscarriage and induced abortion. Ethics \& Medicine: An International Journal of Bioethics, 24, 29-39.

Van, P. (2012-2013). Conversations, coping, and connectedness: a qualitative study of woman who have experienced involuntary pregnancy loss. Omega, 65, 71-85.

Wong, P. T. P. (1998). Implicit theories of meaningful life and the development of the Personal Meaning Profile (PMP). In: P. T. P. Wong, \& P. Fry (eds.), The human quest for meaning: A handbook of psychological research and clinical applications (pp. 111-140). Mahwah, NJ: Lawrence Erlbaum Associates, Inc.
Psychological changes in women after losing a child before birth 